\title{
Evaluation of Tribocharged Electrostatic Beneficiation of Lunar Simulant in Lunar Gravity
}

\author{
Jacqueline W. Quinn ${ }^{1}$, Jim G. Captain ${ }^{2}$, Kyle Weis ${ }^{2}$, Edgardo Santiago-Maldonado ${ }^{1}$, and \\ Steve Trigwell ${ }^{3}$ \\ ${ }^{1}$ NASA, NE-S1, Kennedy Space Center, FL 32899 \\ ${ }^{2}$ QinetiQ North America, ESC-15, Kennedy Space Center, FL 32899 \\ ${ }^{3}$ Sierra Lobo, ESC-24, Kennedy Space Center, FL 32899
}

\section{Abstract}

\section{Introduction}

The lunar regolith has high concentrations of aluminum, silicon, calcium, iron, sodium, and titanium oxides. Liberation of these metals would provide necessary materials for structural and building material fabrication, spare part, machine and tool production, and construction and site preparation in-situ on the moon or other extraterrestrial body (Rao et al 1979). Ilmenite $\left(\mathrm{FeTiO}_{3}\right)$ is a mineral of interest on the moon as a source of iron, titanium, and oxygen (Cameron 1992, Zhao and Shadman 1993) and therefore enrichment of this mineral in the feedstock before processing would be a considerable advantage in reducing energy requirements to process regolith. Not only for construction materials, but shipping oxygen and water from earth is weight prohibitive, and so investigations into the potential production of oxygen from the oxides of lunar regolith are a major research initiative by NASA (Sibille et al. 2009, Moscatello et al. 2009).

On-going bench top and in-vacuo testing indicated significant enrichment greater than $200 \%$ (Trigwell et al 2009) for targeted mineral species using tribocharged beneficiation, however this 
current testing is not able to simulate $1 / 6$ gravity found on the lunar surface. It is believed that a system design for lunar conditions will be greatly influenced by the increased charge accumulated by the regolith particles as they fall through the tribocharger under the slower speed of reduced gravity, the higher charge accumulation due to the lack of atmospheric moisture, and the longer fall times through the separator allowing for enhanced separation. Understanding the benefits of reduced gravity and its design ramifications is essential to successful infusion of a beneficiator into future flight-certified hardware.

With the method of electrostatic beneficiation described herein, dust or powder particles are tribocharged (the act of charging a particle by contact with another material) by materials of a different composition. Particles are charged with positive or negative polarities, depending upon their composition and work function differences relative to the charging material. These charged particles can then undergo electrostatic separation in an electric field based upon their charge-tomass $(\mathrm{q} / \mathrm{m})$ ratio. The efficiency of separation is dependant upon the particle's bulk and surface composition.

Three different charging materials were initially tested in the triboelectrification process: aluminum, copper, and polytetrafluoroethylene (PTFE). These materials were selected because they offer a wide variation in work functions (aluminum $4.28 \mathrm{eV}$, copper $4.65 \mathrm{eV}$, and PTFE $5.75 \mathrm{eV}$ ). The difference between the work function of each material and the simulant influences the charge obtained by the regolith particles. The resulting $\mathrm{q} / \mathrm{m}$ ratio leads to variations in mineral separation when exposed to an electric field. The detailed principle of the operation has been described elsewhere (Trigwell et al 2009). For the RGF work, an aluminum tribocharger was utilized with the goal of enrichment of llmenite to $200 \%$ of starting concentration. 
In this paper, the results of electrostatic beneficiation of two sets of lunar simulants on two different reduced gravity flight series are presented.

\section{Experimental}

Figure 1 depicts the bench top configuration used in vacuum to successfully beneficiate Apollo 14163 regolith. The basic apparatus was modified to fit in the test rack aboard the Zero-G plane, shown in Figure 2.

For the $1^{\text {st }}$ reduced gravity flight, the objective was to test the beneficiation as a function of the electric field. Data was collected at three different voltage settings across the plates, $+/-8 \mathrm{kV},+/-$ $10 \mathrm{kV}$, and $+/-12 \mathrm{kV}$. For this flight, the simulant used was NU-LHT-2M, produced by the United States Geological Survey (Stoeser et al, 2010). This simulant was developed based on the sample information gathered at the Apollo 16 highland landing sites that contained an average ilmenite concentration of $1.05 \mathrm{wt} \%$.

During the parabolas, a controlled release of regolith (1-5 gms/min) was allowed to fall into the charging tube and into the electric field between the plates. The average length of time for each parabola was in the order of 23 seconds. A total of 40 parabolas were flown. The regolith particles were collected in three bins at the bottom of the separator; Bin 1 corresponded to the one nearest the negative voltage plate, Bin 2 was in the middle, and Bin 3 corresponded to the one nearest the positive voltage plate. The regolith was collected from each bin after each set of parabolas and analyzed for composition by secondary electron microscopy/energy dispersive spectroscopy (SEM/EDS). For the matrix and number of samples analyzed, this technique was considered efficient enough to allow for quick turnaround of samples and provide statistically valid data (Trigwell et al. 2011). The compositions were compared to those taken for control preseparated samples. 
For the $2^{\text {nd }}$ reduced gravity flight, the objective was to test the beneficiation at 3 higher voltages than the $1^{\text {st }}$ flight, namely, $+/-13 \mathrm{kV},+/-15 \mathrm{kV}$, and $+/-20 \mathrm{kV}$ using a simulant mixture. The first lesson learned from the 1st flight was that the regolith needed to be properly dried prior to the flight as the presence of moisture on the surface of the particles reduced the acquired charge. For this flight, the regolith was dried in an oven at 130 degrees $\mathrm{C}$ for 24 hrs prior to mixing. The second lesson learned was due to the low content of ilmenite in the NU-LHT-2M simulant $(1.05 \mathrm{wt} \%)$, determining the titanium values to a valid degree of accuracy was difficult.

Therefore samples for this flight were composed of a mixture of 18 gm NU-LHT-2M, mixed with 2 gm of ilmenite. The extra ilmenite was added to provide more validation of beneficiation. A controlled release of regolith at $\sim 3 \mathrm{gms} / \mathrm{min}$ was allowed to fall into the charging tubes. In this flight series, 80 parabolas were flown.

A JEOL-7500F scanning electron microscope with an energy dispersive X-ray spectrometer was used to take images and perform elemental analysis of regolith particles. The SEM field of view (FOV) was set to approximately 400 to $1000 \mu \mathrm{m}$. The instrument is equipped with a Thermo NORAN System Six Energy Dispersive x-ray Spectroscopy system for elemental analysis. Electron beam energies were 1-2 kV during image and $15 \mathrm{kV}$ during the EDS analysis. The sample chamber was held at a pressure of $9.6 \times 10^{-5}$ mbar during imaging and analysis.

\section{Results and Discussion}

\section{$I^{\text {st }}$ reduced gravity flight}

Each parabolic run did not beneficiate enough regolith to run multiple EDS analyses on, and so several parabolas worth of regolith were collect in the bins and analyzed. Therefore the data is presented as Parabolas 1-6, Parabolas 7-13, Parabolas 14-20, and Parabolas 23-30, and is summarized in Tables 1 to 4 . Over 400 analyses were performed in order to gain confidence in 
the data set. The EDS analyses were performed search for the presence of $\mathrm{Ti}$, which is only found in the mineral ilmenite. From the atomic mass detected, the mass differences in tlmenite can be calculated. To determine the validity of the data, a one-way analysis of variance (1-way ANOVA) statistical analysis of the sample data was performed (Howell, 2002). At a 95\% confidence level, there was a statistically significant difference in the ilmenite found in Bins 1 (negative plate) and Bin 2 (middle bin) as compared to Bin 3 (positive plate) for all voltage levels tested. Based upon the indication that the differences between Bins 1 and 3 and Bins 2 and 3 are significant for the first two sets of parabolas, and between all Bins in the last two sets of parabolas, the enrichment of ilmenite was observed to be as high as $65 \%$ in a single pass as summarized in Table 5.

What is interesting to note is that the data shows that as much as $43 \mathrm{wt} \%$ of the total regolith mass ends up in Bin 3 (Table 3), and this mass is significantly lower in ilmenite concentration $(17 \mathrm{wt} \%)$. This translates into less mass that would be heated in a hydrogen reduction reactor to produce up to $60 \%$ more oxygen per batch with only a single enrichment pass. This also suggests that as much as $40 \%$ more regolith would need to be excavated as Bin 3 would not be processed in an oxygen production system. If Bins 1 and 2 were kept for processing and only a single enrichment pass was conducted, an enrichment value of as much as $44 \%$ could be achieved.

Another interesting observation is there was a mechanical failure of the tapper on the charging tube during the last parabola sets (23-30). The feed system was activated, but the charger was gathering charged regolith within its treatment area. This greatly impacted the separation of minerals as indicated by the increase of ilmenite in Bin 1 as opposed to Bin 2 even though the voltages applied were the same. 
$2^{\text {nd }}$ reduced gravity flight

On the first flight, Vials A and B were beneficiated. Vial A was beneficiated during parabolas 218 and the applied voltage on the separator plates of $+/-20 \mathrm{kV}$. During parabolas $19-40$, Vial B was beneficiated with an applied voltage of $+/-15 \mathrm{kV}$.

In between Flights 1 and 2, it was noted upon visual inspection of the simulant collected in the trays that the spread of simulant between the bins was not typical of what was seen during experiments in the lab or on the previous flight. To determine whether this was due to the simulant being drier than usual or if some other factors had caused it, such as orientation on the aircraft and the varying vector of gravity during the parabola, the flight rack was rotated 90 degrees.

On the second flight, Vials $\mathrm{C}$ and $\mathrm{D}$ were beneficiated. Vial C was beneficiated during parabolas 2-20 repeated at the applied voltage of $+/-15 \mathrm{kV}$ - this was done for comparative purposes since the flight rack was rotated. Then, during parabolas 21-40, Vial D was beneficiated with an applied voltage of $+/-13 \mathrm{kV}$.

Vials were emptied onto a piece of aluminum foil and mounted onto ten different pieces of carbon tape (approximately $6 \mathrm{~mm}$ squares) to be placed into the SEM for analysis. The data is summarized in Tables 6 to 9 for the four sets of spiked LHT simulant samples that were beneficiated on the RGF. Each of the vials had exactly the same starting quantities of materials $2.0 \mathrm{~g}$ of ilmenite mixed into $18.0 \mathrm{~g}$ of LHT simulant - or $10 \%$ ilmenite by weight.

From Tables 6-9, It can be seen that there is a significant difference in the concentrations of ilmenite between all bins. In all cases the negative bin had the lowest concentration of ilmenite, and in all cases the middle bin had the highest concentration of ilmenite. There is also a relationship between the voltage applied to the separator plates and the concentration of ilmenite 
in the middles bins, as voltage is increased so does the concentration. It should also be noted the difference in concentration in the middle bin between Vials B and C. The chamber orientation was rotated 90 degrees between Vials $\mathrm{A} / \mathrm{B}$ and $\mathrm{C} / \mathrm{D}$ and Vials $\mathrm{B}$ and $\mathrm{C}$ were duplicate voltage settings to compare any differences that might be encountered due to orientation with respect to the parabolic flight path.

The data shown in another form in Table 10. This table describes \% beneficiation, or how well the sample has been enriched in ilmenite. It is important to note the second statistic as well, \% recovery, which describes how much of the starting ilmenite is found in that bin. It is preferable to have high values of each, but a balance must be struck in order to yield truly positive results. High beneficiation and low yield means there is too little recoverable material to work with and it might not be worth the material losses from an excavation perspective. High yield and low beneficiation means you still have a large bulk of your material which is only minimally enriched, meaning you still have a large energy requirement for many oxygen production processes.

One of the most important pieces of data to come out of this flight test was that the orientation of the rack on the aircraft had noticeable affects on the data. When the bins that collected soil were oriented perpendicular to the flight path, there was a noticeable decrease in $\%$ beneficiation and $\%$ recovery at $+/-15 \mathrm{kV}$ as compared to when the bins were oriented parallel to the flight path. This is likely because the effects of gravity are still felt on the particles with the smallest charge to mass ratios. Coupled with the fact that at the start and end of every parabola the force of gravity is not perpendicular to the bottom of the aircraft, this could cause a sufficient number of particles to be transported into bins based on the direction of gravity and not by electrostatic forces. By orienting the bins parallel to the flight path, the force of gravity will cause the soil to 
fall along the center of the collection bin allowing electrostatics to be the driving force for soil enrichment.

\section{Conclusions}

The reduced gravity flight confirmed data gather in the laboratory that tribocharged electrostatic beneficiation of NU-LHT-2M lunar simulant has the ability to enrich for the targeted mineral ilmenite. The success of the technology was statistically verified using 1-Way ANOVA analysis. In the $1^{\text {st }}$ RGF, the enrichment that was achieved in a single pass was as high as $65 \%$ in a single collection bin.

In the $2^{\text {nd }} R G F$, the enrichment that was achieved in a single pass was as high as $106 \%$ in a single collection bin. Because of the limited number of experiments, a duplicate of $+/-20 \mathrm{kV}$ with the flight rack in the second orientation was not able to be performed but the comparison of data between the two $+/-15 \mathrm{kV}$ samples suggests it could provide positive results. This duplicate data, as well as a maximum applied voltage of $+/-26 \mathrm{kV}$ would be promising data sets to collect on a future flight.

Tribocharged electrostatic beneficiation is a viable contender for the reduced gravity experienced on Earth's Moon and should be explored further.

\section{References}

Cameron, E.N. (1992). “Apollo 11 Ilmenite Revisited”. Space 92, The 3rd International

Conference on Engineering, Construction, and Operations in Space. Denver, CO. WCSAR-TRAR3-9201-3.

Captain, J.G., Trigwell, S., Arens, E.E., Biris, A.S., Captain, J.E., Quinn, J.W., and Calle, C.I. (2007). "Tribocharging Lunar Simulant in Vacuum for Electrostatic Beneficiation", AIP Conf. Proc., 880, STAIF 2007, Albuquerque, NM, 951-956. 
Heiken, G.H., Vaniman, D.T., and B.M. French, B.M. (Eds.). (1993). Lunar Source Book: A user's guide to the moon, UK: Cambridge University Press.

Hintze, P.E., Curran, J., and Back, T. (2009). "Lunar Surface Stabilization via Sintering or the use of Heat Cured Polymers," Proc. $47^{\text {th }}$ AIAA Aerospace Sciences Meeting, Orlando, FL. AIAA 2009-1015

Howell, D., (2009). Statistical methods for Psychology, Wadsworth, CA.

Immer, C.D., Metzger, P.T., Nick, A., and Horan, R. (2011). “Apollo 12 lunar module exhaust plume impingement on lunar Surveyor III”, Icarus, 211(2), 1089-1102.

Inculet, I.I., Bergougnou, M.A., and Brown, J.D. (1982). "Physical Cleaning of Coal - Present and Developing Methods", Y.A. Liu [Ed.], Marcel Dekker, New York, Metzger P.T., Li, X., Immer, C.D., and Lane, J. (2009). "ISRU implications of lunar and Martian plume effects", Proc. $47^{\text {th }}$ AIAA Aerospace Sciences Conference, Orlando, FL, AIAA 20091204.

Moscatello, A.C., Captain, J.E., Quinn, J.W., Gibson, T.L., Perusich, S.A., and Weis, K.H. (2009). “Lunar Water Demonstration (LWRD) Test Results”, Proc. AIAA SPACE 2009 Conference and Exposition, Pasadena, CA. AIAA 2009-6474.

Rao, D.B., Choudary, U.V., Erstfeld, T.E., Williams, R.J., and Chang, Y.A., (1979). "Extraction Processes for the Production of Aluminum, Titanium, Iron, Magnesium, and Oxygen from Nonterrestrial Materials". Space Resources and Space Settlements, NASA SP-428, pp. 257-274. Sibille, L., Sadoway, D.R., Sirk, A., Tripathy, P., Melendez, O., Standish, E., Dominguez, J.A., Stefanescu, D.M., Curreri, P.A., and Poizeau, S. (2009). "Recent Advances in Scale-up Development of Molten Regolith Electrolysis for Oxygen Production in support of a Lunar Base", Proc. $47^{\text {th }}$ AIAA Aerospace Sciences Meeting, Orlando, FL, AIAA 2009-659. 
Stoeser, D., Wilson, S., and Rickman D. (2010). "Design and specifications for the Highland Regolith Prototype Simulants NU-LHT-1M and -2M”, NASA Technical report NASA/TM2010-216438, Marshal Space flight Center, AL.

Trigwell, S., Captain, J.G., Arens, E.E., Quinn, J.W., and Calle, C.I. (2009). The use of Tribocharging in the Electrostatic Beneficiation of Lunar Simulant”. IEEE Trans. Ind. Apps., 45(3), 1060-1067.

Trigwell, S., Captain, J.G., Captain, J.E., Arens, E.E., Quinn, J.W., and Calle, C.I. (2006).

"Electrostatic Beneficiation of Lunar Simulant", Proc. ESA/IEJ/IEEE-IAS Joint Conference, UC Berkeley, CA, 297-306.

Trigwell, S. (2002). "Correlation between Surface Structure and Tribocharging of Powders", PhD Dissertation, University of Arkansas at Little Rock, Little Roc, AR.

Trigwell, S., Lane, J., Captain J.G., Weis K., Quinn, J.W., and Watanabe, F. (2011).

"Quantification of Efficiency of Beneficiation of Lunar Regolith", to be submitted to Particulate Science and Technology.

Zhao, Y., and Shadman, F. (1993). "Production of oxygen from lunar ilmenite". In Resources of Near Earth Space, J. Lewis, M.S. Mathews, and M.L. Guerrier, eds., University of Arizona Press, AZ. 149-178. 


\section{Figure captions}

Figure 1. Bench top electrostatic beneficiation apparatus.

Figure 2. Test rack containing the electrostatic beneficiation apparatus for installation in the Zero-G plane.

Figure 3. Orientation of the separator collector bins to the flight direction 


\section{Table captions}

Table 1. Parabolas 1-6 Voltage $+/-10 \mathrm{kV}$

Table 2. Parabolas 7-13 Voltage $+/-8 \mathrm{kV}$

Table 3. Parabolas 14-20 Voltage $+/-12 \mathrm{kV}$

Table 4. Parabolas 23-30 Voltage $+/-12 \mathrm{kV}$

Table 5. Ilmenite enrichment for each bin in the separator for each set of parabola flights.

Table 6. Vial A $+/-20 \mathrm{kV}$

Table 7. Vial B +/- $15 \mathrm{kV}$

Table 8. Vial C +/- $15 \mathrm{kV}$

Table 9. Vial D +/- $13 \mathrm{kV}$

Table 10. Ilmenite enrichment for each bin in the separator for each set of Vials. 


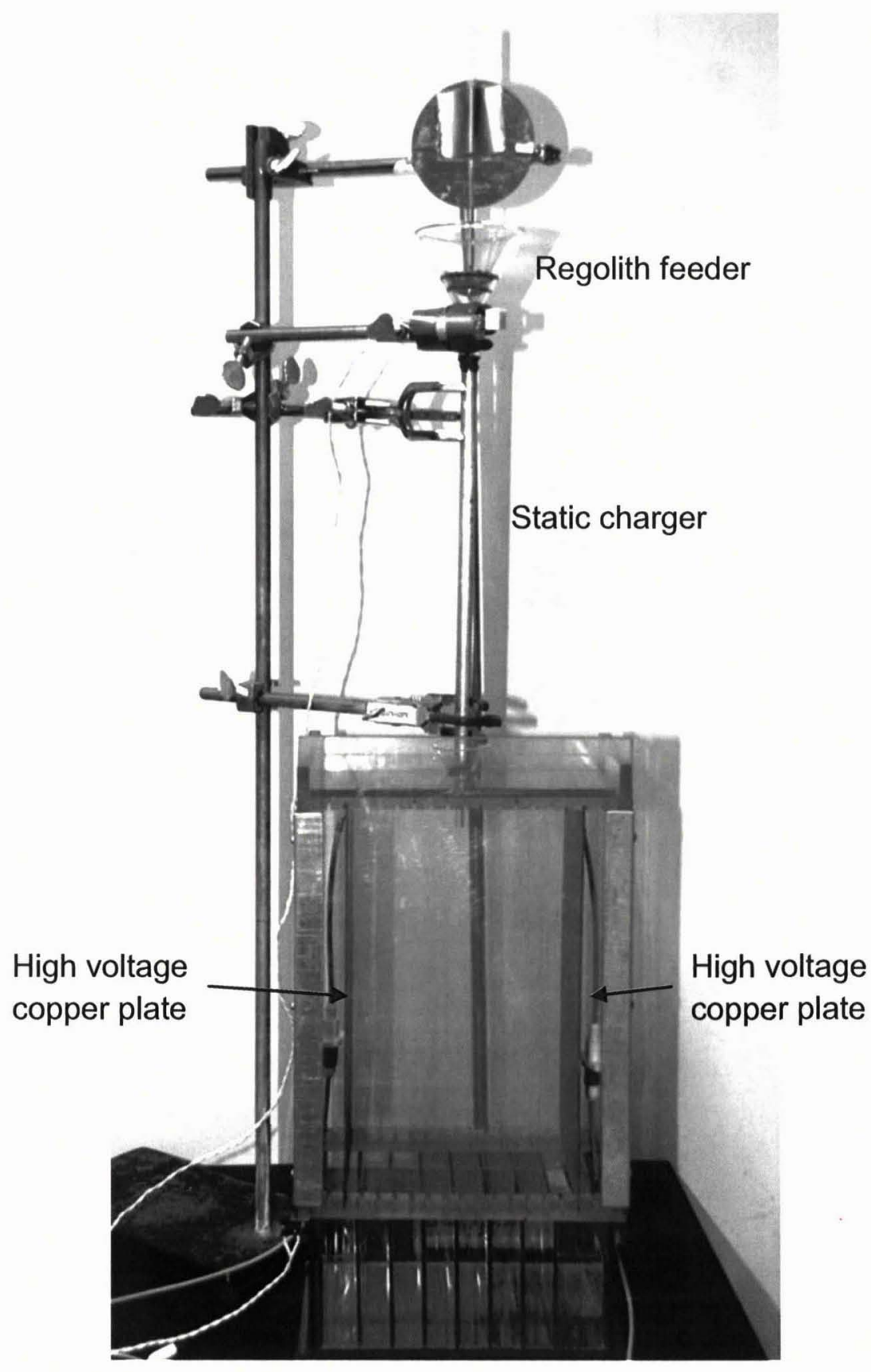

Collection bins

Fig. 1. 


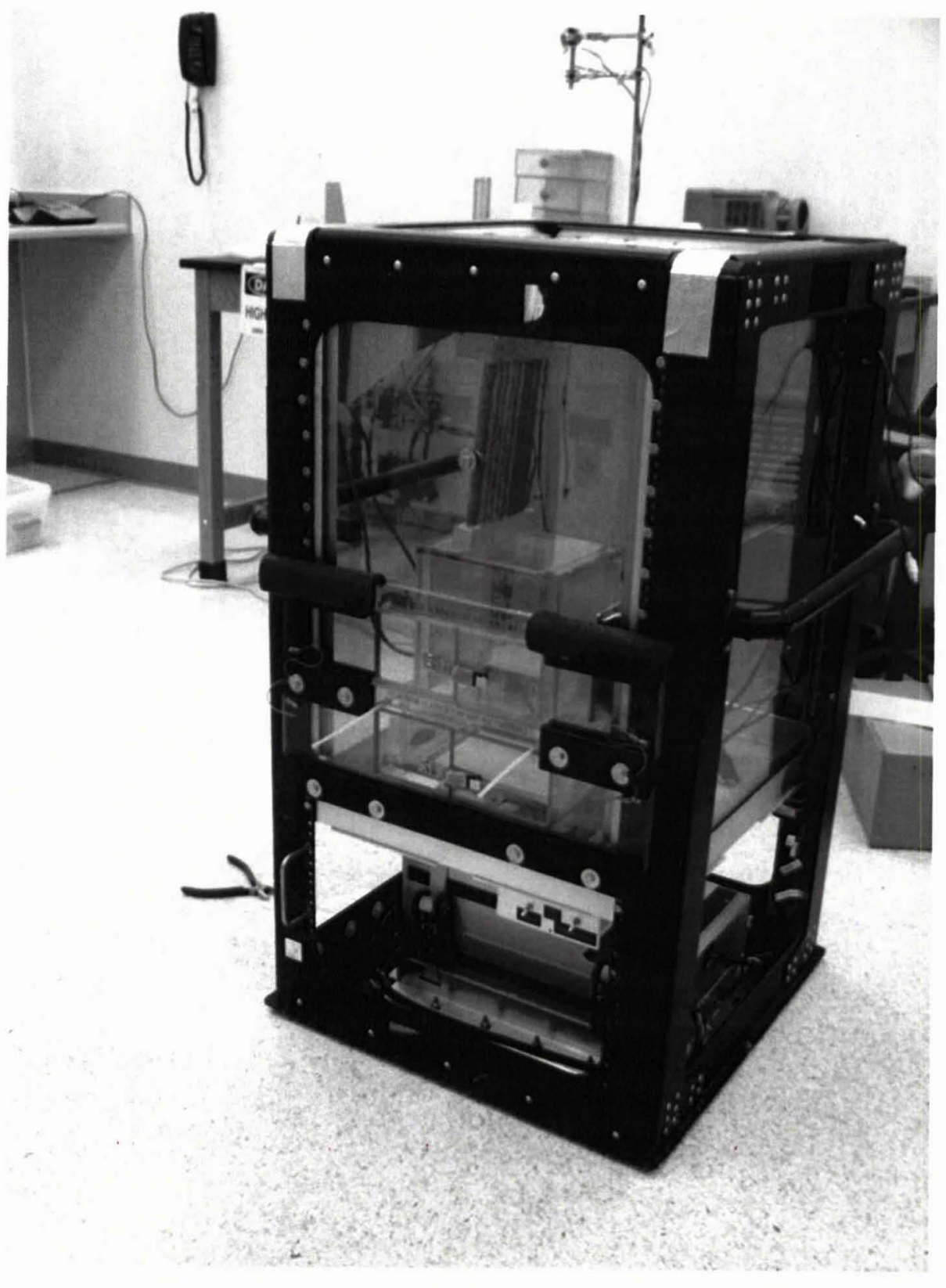

Fig. 2. 
The arrow represents the direction of travel

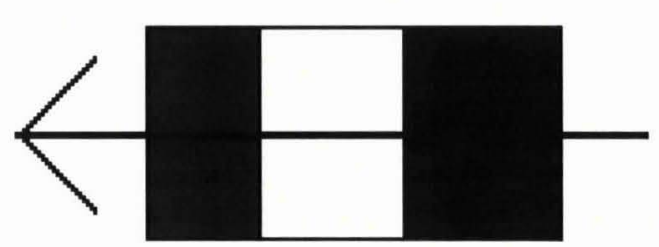

Orientation of bins during Flight 1 - perpendicular (vials $A$ and $B$ )

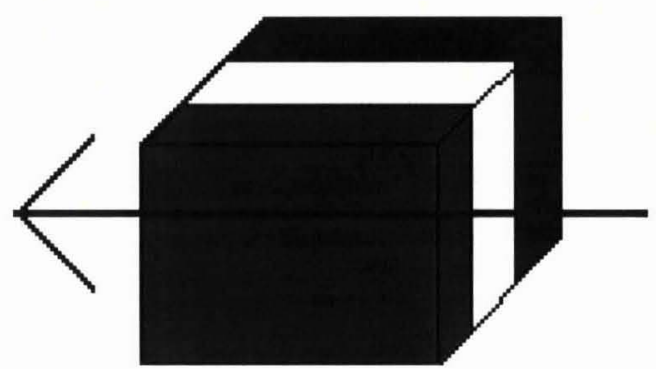

Orientation of bins during Flight 2 - parallel (vials $C$ and $D$ )

Fig. 3. 
Table 1.

\begin{tabular}{|c|c|c|c|c|}
\hline & Bin1 & Bin2 & Bin3 & $\begin{array}{c}\text { Total mass } \\
\text { collected in } \\
\text { Bin }\end{array}$ \\
\hline Average ilmenite wt\% & 1.94 & 2.17 & 0.48 & \\
\hline Total LHT mass (g) & 0.90 & 3.46 & 1.70 & 6.06 \\
\hline Ilmenite mass (g) & 0.017 & 0.075 & 0.008 & 0.10 \\
\hline
\end{tabular}


Table 2.

\begin{tabular}{|c|c|c|c|c|}
\hline & Bin1 & Bin2 & Bin3 & $\begin{array}{c}\text { Total mass } \\
\text { collected in } \\
\text { Bin }\end{array}$ \\
\hline Average ilmenite wt\% & 1.22 & 1.55 & 0.62 & \\
\hline Total LHT mass (g) & 0.44 & 3.61 & 1.20 & 5.25 \\
\hline Ilmenite mass (g) & 0.005 & 0.056 & 0.007 & 0.07 \\
\hline
\end{tabular}


Table 3.

\begin{tabular}{|c|c|c|c|c|}
\hline & Bin1 & Bin2 & Bin3 & $\begin{array}{c}\text { Total mass } \\
\text { collected in } \\
\text { Bin }\end{array}$ \\
\hline Average ilmenite wt\% & 1.64 & 2.76 & 0.72 & \\
\hline Total LHT mass (g) & 0.87 & 2.71 & 2.67 & 6.25 \\
\hline Ilmenite mass (g) & 0.014 & 0.075 & 0.019 & 0.11 \\
\hline
\end{tabular}


Table 4.

\begin{tabular}{|c|c|c|c|c|}
\hline & Bin1 & Bin2 & Bin3 & $\begin{array}{c}\text { Total mass } \\
\text { collected in } \\
\text { Bin }\end{array}$ \\
\hline Average ilmenite wt\% & 3.06 & 2.26 & 0.96 & \\
\hline Total LHT mass (g) & 1.31 & 3.79 & 3.50 & 8.60 \\
\hline Ilmenite mass (g) & 0.040 & 0.086 & 0.034 & 0.16 \\
\hline
\end{tabular}


Table 5.

\begin{tabular}{|c|c|c|c|}
\hline Parabola Set & $\%$ Beneficiation Bin 1 & $\%$ Beneficiation Bin 2 & $\%$ Beneficiation Bin 3 \\
\hline $1-6$ & $17 \%$ & $31 \%$ & $-71 \%$ \\
\hline $7-13$ & $-7 \%$ & $18 \%$ & $-53 \%$ \\
\hline $14-20$ & $-5 \%$ & $59 \%$ & $-59 \%$ \\
\hline $23-30$ & $65 \%$ & $22 \%$ & $-48 \%$ \\
\hline
\end{tabular}


Table 6.

\begin{tabular}{|c|c|c|c|c|c|}
\hline Vial A +/- $20 \mathrm{kV}$ & negative bin & middle bin & positive bin & total recovery & \% recovery \\
\hline Average ilmenite wt\% & $7.4 \%$ & $20.6 \%$ & $14.3 \%$ & & \\
\hline Total LHT mass (g) & 7.8 & 2.5 & 7.4 & 17.7 & $89 \%$ \\
\hline Ilmenite mass (g) & 0.574 & 0.514 & 1.061 & 2.15 & $107 \%$ \\
\hline
\end{tabular}


Table 7.

\begin{tabular}{|c|c|c|c|c|c|}
\hline Vial B $+/-15 \mathrm{kV}$ & negative bin & middle bin & positive bin & total recovery & $\%$ recovery \\
\hline Average ilmenite wt\% & $6.8 \%$ & $15.7 \%$ & $12.8 \%$ & & \\
\hline Soil mass (g) & 7 & 3 & 7.2 & 17.2 & $86 \%$ \\
\hline Ilmenite mass (g) & 0.477 & 0.472 & 0.923 & 1.87 & $94 \%$ \\
\hline
\end{tabular}


Table 8.

\begin{tabular}{|c|c|c|c|c|c|}
\hline Vial C +/- 15kV & negative bin & middle bin & positive bin & total recovery & $\%$ recovery \\
\hline Average ilmenite wt\% & $6.4 \%$ & $17.6 \%$ & $9.5 \%$ & & \\
\hline Soil mass (g) & 6.1 & 4.2 & 8.6 & 18.9 & $95 \%$ \\
\hline Ilmenite mass (g) & 0.389 & 0.741 & 0.814 & 1.94 & $97 \%$ \\
\hline
\end{tabular}


Table 9.

\begin{tabular}{|c|c|c|c|c|c|}
\hline Vial D +/- $13 \mathrm{kV}$ & negative bin & middle bin & positive bin & total recovery & $\%$ recovery \\
\hline Average ilmenite wt $\%$ & $6.1 \%$ & $15.3 \%$ & $10.5 \%$ & & \\
\hline Soil mass (g) & 5.3 & 5.6 & 7.8 & 18.7 & $94 \%$ \\
\hline Ilmenite mass (g) & 0.321 & 0.854 & 0.823 & 2.00 & $100 \%$ \\
\hline
\end{tabular}


Table 10.

\begin{tabular}{|c|c|c|c|c|c|c|}
\hline \multirow{2}{*}{} & \multicolumn{2}{|c|}{ negative bin } & \multicolumn{2}{c|}{ middle bin } & \multicolumn{2}{c|}{ positive bin } \\
\hline Vial & Beneficiation & Recovery & Beneficiation & Recovery & Beneficiation & Recovery \\
\hline $\mathrm{A}+/-20 \mathrm{kV}$ & $-26 \%$ & $27 \%$ & $106 \%$ & $24 \%$ & $43 \%$ & $49 \%$ \\
\hline $\mathrm{B}+/-15 \mathrm{kV}$ & $-32 \%$ & $25 \%$ & $57 \%$ & $25 \%$ & $28 \%$ & $49 \%$ \\
\hline $\mathrm{C}+/-15 \mathrm{kV}$ & $-36 \%$ & $20 \%$ & $76 \%$ & $38 \%$ & $-5 \%$ & $42 \%$ \\
\hline $\mathrm{D}+/-13 \mathrm{kV}$ & $-39 \%$ & $16 \%$ & $53 \%$ & $43 \%$ & $5 \%$ & $41 \%$ \\
\hline
\end{tabular}

